\title{
MODIFIED QUADRATIC BUCK BOOST CONVERTER FOR PV APPLICATIONS
}

\author{
Aparna Mohan S \\ PG Scholar, Dept of EEE \\ Government Engineering College, \\ Bartonhill, Thiruvananthapuram
}

\author{
Prof. Anjana K R \\ Associate Professor, Dept of EEE \\ Government Engineering College, \\ Bartonhill, Thiruvananthapuram
}

\begin{abstract}
Buck-boost DC/DC converters have been extensively employed in stepping up/down the voltage for PV applications. The input and the output port current of the traditional quadratic buck-boost converter are discontinuous, which result in increased input and output current ripples and complicate the design of the input and output filters. Hence these problems can be solved by using a modified quadratic buck boost converter, which provides wider voltage conversion ratio with continuous input and output ports current. Dual output can be derived from this single input converter for multiple output applications. Also a fuzzy logic controller can be designed for this proposed converter for better and faster performance.
\end{abstract}

Index Terms-Buck-boost DC/DC converters, voltage conversion ratio, quadratic buck boost converter, FLC

\section{INTRODUCTION}

Nowadays, renewable energy systems such as fuel cell stacks and photovoltaic power systems are becoming one of the most attractive and promising sources of providing electrical energy compared to the conventional fossil fuel energy generating sources. With the elevation of the power electronic technology, awareness about the effects of exhaustible energy sources on the environment, the employment of inexhaustible energy sources have gained more importance as a future energy source. However, these alternative energy systems have an output, whose voltage is variable, depending on various environmental conditions. Works related to quadratic relationship of input and output voltages are recently analysed because of its wider conversion ratio[1]-[2]. Plenty of studies have been flourished and described on quadratic buck converters, where some investigations have been done on the mathematical modelling, methods of control [3]-[7] and quadratic boost converters where its novel topologies[8]-[11] were analyzed . But only a few investigations are done on quadratic buck-boost converters. These converters are less expensive, better structured besides the regular quadratic boost converter.

Few research works on conventional quadratic buck-boost converters which is created by combining two conventional buck-boost converters where the input and output current are not continuous [12] and the application area where the converter can be used like energy stocking devices similarly batteries/supercapacitors with electrical and electrochemical principle was analysed [13].

High step up/step down voltage gain can be obtained by using a transformer less buck boost converter [14]. Even though its construction is simple, it produces naturally discontinuous input and output current. Two synchronously operating switches are responsible for their discontinuous input and output waveforms. The soft switching in this converter was obtained by introducing two resonant networks [15]. The switches are not subjected to high switch voltage or current stresses and, consequently, present low conduction losses. But it consist of more number of components than other configurations. So these limitation is solved by using single switch quadratic buck boost converter. As the name suggests, it consists of only one switch.

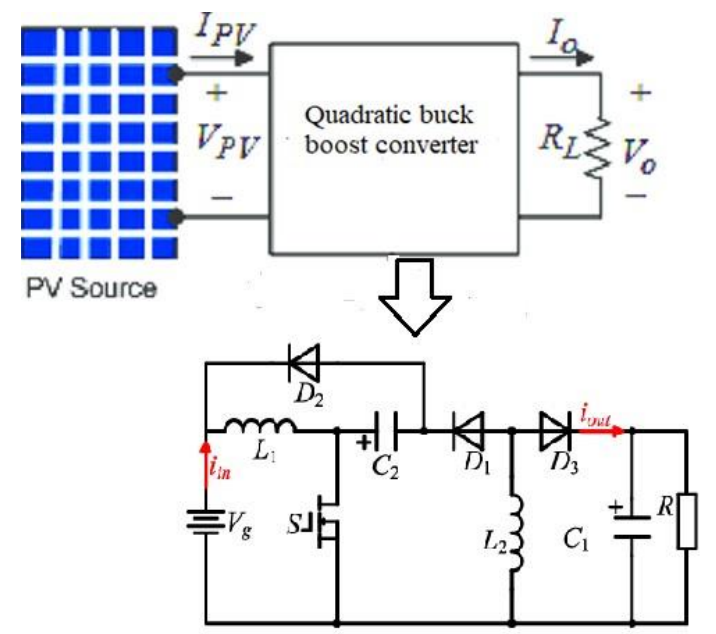

Fig. 1. Traditional quadratic buck boost converter system

Traditional quadratic buck-boost converter as shown in Fig.1, encounters increased input and output ripple currents with discontinuous input and output currents causing complexity in construction of $\mathrm{i} / \mathrm{p}$ and o/p filters [16]-[17]. It is formed by combining two ordinary step-down-up converters. 


\section{International Journal of Engineering Applied Sciences and Technology, 2021 \\ Vol. 6, Issue 1, ISSN No. 2455-2143, Pages 181-189 \\ Published Online May 2021 in IJEAST (http://www.ijeast.com)}

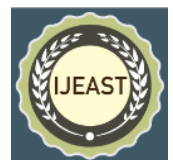

As the inductor current is alike to the $\mathrm{i} / \mathrm{p}$ current during turn on of switch, the $L_{2}$ inductor current is alike to the o/p current during switch turn off. Hence the input and output current are not continuous. This was overcame by quadratic buck boost converter with continuous input and output port current, which uses only one switch as in Fig. 2.

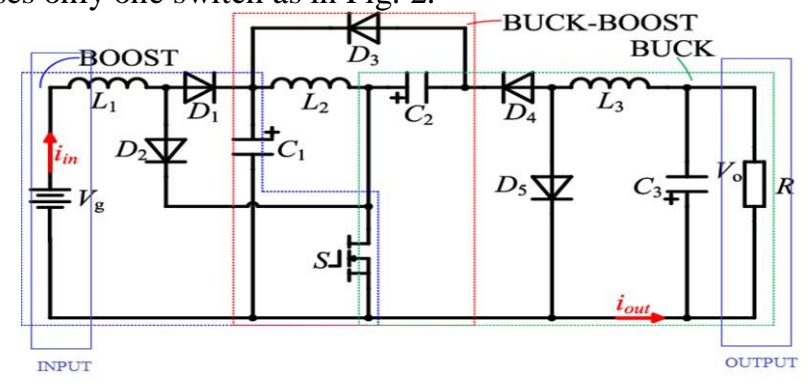

Fig. 2. Existing Converter

But for many applications, well-regulated power supplies with multiple outputs are needed. In the modern world fields such as industries, telecommunication, LED drivers, dc based nano grid etc. require multiple output because of the auxiliary circuits present in those system other than main circuit [18].So that the researches on single input multiple output DC-DC converters are going on in order to get a less bulky system and more reliable control strategy.

So a dual output quadratic buck boost converter with continuous input and output port current controlled by a fuzzy logic controller is proposed for faster and stable response control. It uses only one switch. The ripples present in output current and output voltage are lower than the proposed structures in existing literature. The modified converter has wide range of voltage conversion ratio with same duty cycle.

\section{PROPOSED SYSTEM}

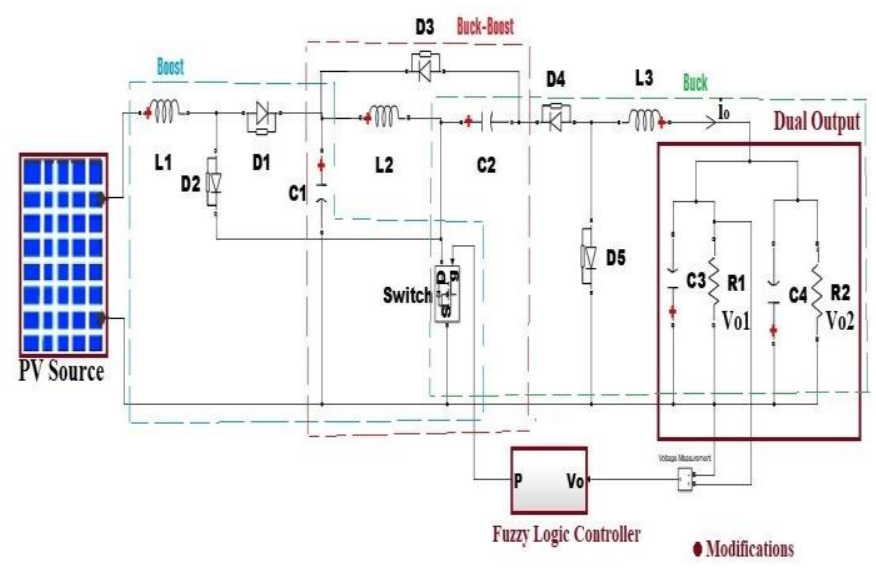

Fig. 3. Proposed System
Fig. 3 shows the overall circuit of proposed system. It is mainly composed of three different types of converters. First at the beginning of the circuit, there is a boost converter, followed by a buck-boost converter as an intermediate stage and finally a buck converter is placed as the last stage of the converter. It employs a single switch that is placed such that it can control the three different sections at the same time. The boost converter consists of input source $V_{i n}$, diodes $D_{1}$ and $D_{2}$, inductor $L_{1}$, capacitor $C_{1}$, and switch $\mathrm{S}$. The buck-boost converter consists of capacitors $C_{1}$ and $C_{2}$, inductor $L_{2}$, diode $D_{3}$, and switch S. The buck converter consists of capacitors $C_{2}$, $C_{3}$ and $C_{4}$, diodes $D_{4}$ and $D_{5}$, inductor $L_{3}$, switch $\mathrm{S}$, and load resistors $R_{1}$ and $R_{2}$. And also $V_{o 1}=V_{o 2}=V_{o}($ Output voltage $)$. It can be seen that the output capacitor of the boost converter is the input source of the buck-boost converter while the output of the buck-boost converter is the input source of the buck converter. It is of interest to note that there is an inductor connected in the input port and an inductor connected in the output port of the converter, which can contribute to the unique feature of drawing continuous input port current and continuous output port current.

With the help of fuzzy logic controller we can regulate the output as per the need of voltage requirement. Required level of output voltage can be maintained by the employment of closed loop control thereby enhancing production of system. With the help of this control techniques settling time of the output voltage can be reduced.For comparing the performance of fuzzy logic controller, PI controller based on tyreus Luyben(T-L) tuning method is formulated.

$$
\text { Conversion ratio of converter, } M=\frac{V o}{V i n}=\left(\frac{D}{1-D}\right)^{2}
$$

When the duty ratio(D) is below $50 \%$, the converter act as buck and when the duty ratio is above $50 \%$, the converter act as boost converter. The working of the circuit can be explained by two modes of operation.

Similar to other buck-boost converters, the proposed converter can theoretically operate in both continuous inductor current mode and discontinuous inductor current mode. However, since the continuous inductor current mode is normally preferred in many industrial applications to reduce the current ripple and also operating with continuous input and output current is a main benefit of the proposed converter.

\section{A. Operation of Converter}

When the switch is turned on, all of the diodes 1, 3, and 5 are turned off while diodes 2 and 4 are turned on as shown in Fig. 4. On the contrary, when the switch is off, diodes 2 and 4 are off while diodes 1, 3, and 5 are on as shown in Fig. 5. At this point, each mode has its own component function and behavior, which is different from the other sections and it is explained in the following subsections.

1) Mode 1: As shown in figure 4, the switch $\mathrm{S}$ is conducting, diodes D2 and D4 are in ON state, and diodes $D_{1}$, 
$D_{3}$, and $D_{5}$ are reverse-biased by $v_{C 1}, v_{C 1}+v_{C 2}$, and $v_{C 2}$, respectively. The input source $V_{\text {in }}$ delivers power to the inductor $L_{1}$ through the diode $D_{1}$ and the switch S, meantime, the energy stored in capacitors $C_{1}$ and $C_{2}$ is being released to inductors $L_{2}$ and $L_{3}$, respectively. Some of the main equations among the components in this mode are as follows:

$$
\begin{gathered}
L_{1} \frac{d i_{L 1}}{d t}=V_{g}, \quad L_{2} \frac{d i_{L 2}}{d t}=V_{c 1}, \quad L_{3} \frac{d i_{L 3}}{d t}=V_{c 2}-V_{o} \\
C_{1} \frac{d i_{V_{c 1}}}{d t}=i_{L 2}, \quad C_{2} \frac{d V_{c 2}}{d t}=i_{L 3} \\
C_{3} \frac{d V_{o}}{d t}=C_{4} \frac{d V_{o}}{d t}=i_{L 3}-\frac{V_{o}}{R}
\end{gathered}
$$

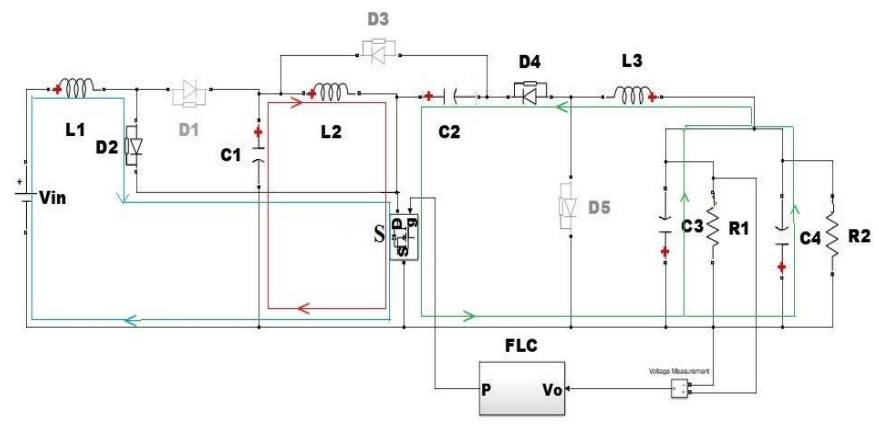

Fig. 4. Mode 1

2) Mode 2 : As shown in Fig. 5, the switch $\mathrm{S}$ is turned OFF, diodes $D_{1}, D_{3}$, and $D_{5}$ are in ON state, and diodes $D_{2}$ and $D_{4}$ are reverse-biased by $v_{C 2}$ and $v_{C 1}$, respectively, in this operating mode. The energy stored in the inductor $L_{1}$ as well as the input source is delivered to the capacitor $C_{1}$, and the capacitor $C_{1}$ starts to store energy. The inductor $L_{2}$ discharges energy to the capacitor $C_{2}$ through the diode $D_{3}$. At the same time, the inductor $L_{3}$ discharges energy to the capacitor $C_{3}$ and $C_{4}$ and load resistors.Some of the main equations among the components in this mode are as follows:

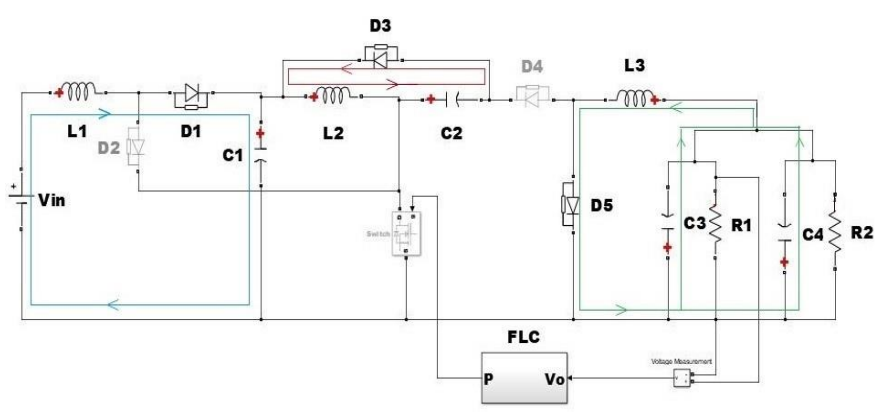

Fig. 5. Mode 2

$$
\begin{gathered}
L_{1} \frac{d i_{L 1}}{d t}=V_{g}-V_{c 1}, \quad L_{2} \frac{d i_{L 2}}{d t}=-V_{c 2}, \quad L_{3} \frac{d i_{L 3}}{d t}=-V_{o} \\
C_{1} \frac{d i_{V_{c 1}}}{d t}=-i_{L 1}, \quad C_{2} \frac{d V_{c 2}}{d t}=-i_{L 2} \\
C_{3} \frac{d V_{o}}{d t}=C_{4} \frac{d V_{o}}{d t}=i_{L 3}-\frac{V_{o}}{R}
\end{gathered}
$$

\section{STATE SPACE REPRESENTATION OF SYSTEM}

The quadratic buck boost converter is assumed to be in continuous conduction mode and few assumptions like all the components are ideal are taken into consideration. The converter is analysed in two switching modes, ie. Mode 1 is when the switch is turned ON [DT] and Mode 2 when switch is turned OFF [(1-D)T].By considering the state space equations in each of these intervals and combining gives the final model representation. The state space model of system can be represented by following state and output equation respectively.

\section{A. Mode 1}

$$
\begin{aligned}
& x^{\cdot}=A x+B u \\
& y=C x+D u
\end{aligned}
$$

The currents flow through inductors $L_{1}, L_{2}$, and $L_{3}$, i.e., $i_{L 1}$, $i_{L 2}$, and $i_{L 3}$ are increasing $\left(t_{0}\right.$ to $\left.t_{1}\right) . \mathrm{Eq}(2)$ and $\mathrm{Eq}(3)$ can be rearranged as follows:

$$
\begin{gathered}
\frac{d i_{L 1}}{d t}=\frac{V_{g}}{L_{1}}, \quad \frac{d i_{L 2}}{d t}=\frac{V_{c 1}}{L_{2}}, \quad \frac{d i_{L 3}}{d t}=\frac{V_{c 2}}{L_{3}}-\frac{V_{o}}{L_{3}} \\
\frac{d i_{V_{c 1}}}{d t}=\frac{i_{L 2}}{C_{1}}, \quad \frac{d V_{c 2}}{d t}=\frac{i_{L 3}}{C_{2}} \\
\frac{d V_{o}}{d t}=\frac{i_{L 3}}{C_{3}}-\frac{V_{o}}{R C_{3}}
\end{gathered}
$$

B. Mode 2

Inductor currents $i_{L 1}, i_{L 2}$, and $i_{L 3}$ are decreasing .Eq(4) and $\mathrm{Eq}(5)$ can be rearranged as follows:

$$
\begin{gathered}
\frac{d i_{L 1}}{d t}=\frac{V_{g}}{L_{1}}-\frac{V_{c 1}}{L_{1}}, \quad \frac{d i_{L 2}}{d t}=\frac{-V_{c 2}}{L_{2}}, \quad \frac{d i_{L 3}}{d t}=\frac{-V_{o}}{L_{3}} \\
\frac{d V_{c 1}}{d t}=\frac{-i_{L 1}}{C_{1}}, \quad \frac{d V_{c 2}}{d t}=\frac{-i_{L 2}}{C_{2}}, \\
\frac{d V_{o}}{d t}=\frac{i_{L 3}}{C_{3}}-\frac{V_{o}}{R C_{3}}
\end{gathered}
$$

Equations for both mode-1 [DT] and mode-2 [(1-D)T] can be combined together for analysis.

Combining eq(4) and eq(7), 


$$
\begin{gathered}
\frac{d i_{L 1}}{d t}=\frac{V_{g} D}{L_{1}}+\frac{V_{g}(1-D)}{L_{1}} \\
\frac{d i_{L 1}}{d t}=\frac{V_{g}}{L_{1}} \\
\frac{d i_{L 2}}{d t}=\frac{V_{c 1} D}{L_{2}}+\frac{-V_{c 2}(1-D)}{L_{2}} \\
d i \quad V \quad D \quad V D \quad V \quad D \\
\frac{L 3}{d t}=\frac{c 2}{L_{3}}-\frac{o}{L_{3}}+\frac{-{ }_{o}\left(1-{ }^{2}\right)}{L_{3}} \\
\frac{d i_{L 3}}{d t}=\frac{V_{c 2} D}{L_{3}}-\frac{V_{o}}{L_{3}}
\end{gathered}
$$

Combining eq(5) and eq(7),

$$
\begin{gathered}
\frac{d i_{V_{c 1}}}{d t}=\frac{i_{L 2} D}{C_{1}}+\frac{-i_{L 1}(1-D)}{C_{1}} \\
\frac{d V_{c 2}}{d t}=\frac{i_{L 3} D}{C_{2}}+\frac{-i_{L 2}(1-D)}{C_{2}} \\
\frac{d V_{o}}{d t}=\frac{i_{L 3} D}{C_{3}}-\frac{V_{o} D}{R C_{3}}+\frac{i_{L 3}(1-D)}{C_{3}}-\frac{V_{o}(1-D)}{R C_{3}} \\
\frac{d V_{o}}{d t}=\frac{i_{L 3}}{C_{3}}+\frac{-V_{o}}{R C_{3}}
\end{gathered}
$$

The above equations can be represented as state space model as shown below in eq(16).

Choose the state variable as $i_{L 1}=x 1, i L 2=x_{2}, i_{L 3}=x_{3}, V_{C 1}=x_{4}$, $V_{C 2}=x_{5}, V_{0}=V_{C 3}=V_{C 4}=x_{6}, u=V_{i n}, y=V_{0}$.

$$
\begin{aligned}
{\left[\begin{array}{l}
\hat{x}_{1} \\
\hat{x}_{2} \\
\hat{x}_{3} \\
\hat{x}_{4} \\
\hat{x}_{5} \\
\hat{x}_{6}
\end{array}\right]=\left[\begin{array}{cccccc}
0 & 0 & 0 & \frac{D-1}{L_{1}} & 0 & 0 \\
0 & 0 & 0 & \frac{D}{L_{2}} & \frac{D-1}{L_{2}} & 0 \\
0 & 0 & 0 & 0 & \frac{D}{L_{3}} & \frac{-1}{L_{3}} \\
\frac{D-1}{C_{1}} & \frac{D}{C_{1}} & 0 & 0 & 0 & 0 \\
0 & \frac{D-1}{C_{2}} & \frac{D}{C_{2}} & 0 & 0 & 0 \\
0 & 0 & \frac{1}{C_{3}} & 0 & 0 & \frac{-1}{R C_{3}}
\end{array}\right]\left[\begin{array}{l}
x_{1} \\
x_{2} \\
x_{3} \\
x_{4} \\
x_{5} \\
x_{6}
\end{array}\right]+\left[\begin{array}{c}
\frac{1}{L_{1}} \\
0 \\
0 \\
0 \\
0 \\
0
\end{array}\right][u] } \\
y=\left[\begin{array}{llllll}
0 & 0 & \frac{-1}{L_{3}} & 0 & 0 & \frac{-1}{R C_{3}}
\end{array}\right]\left[\begin{array}{c}
x_{1} \\
x_{2} \\
x_{3} \\
x_{4} \\
x_{5} \\
x_{6}
\end{array}\right](16)
\end{aligned}
$$

\section{CONTROLLER DESIGN}

Controller based on fuzzy logic and PI controller based on Tyreus-Luyben were designed for the proposed system.

\section{A. PI controller}

In the simple PI controller, the Ziegler-Nichols tuning procedure works quite well, but this method is laborious and time consuming. There are many tuning rules to determine the tuning parameters systematically. However, poorly tuned PI controllers are often found in industry.

One of the keys to overcome this problem is that the tuning rules should be simple and applicable to a wide range of processes. The methods of Tyreus and Luyben, along with the most accepted PI tuning rule given by Ziegler and Nichols ( $\mathrm{Z}-$ $\mathrm{N}$ ), is more conservative approach and provide disturbance less response.

PI controller based on Tyreus Luben(T-L) method was also designed for the system to analyze the controller performance. For TL method calculation, system must be in sustained periodic oscillation and this is obtained when proportional gain is increased to a certain value and this value is called ultimate gain, $K_{u}$ and time period of one such oscillation obtained is called ultimate period, $P_{u}$.

Sustained oscillation for both buck and boost mode is obtained as shown in Fig. 6 and Fig. 7. With these values $K_{p}=0.31^{*} K_{u}$ and $K_{i}=\left(0.31 * K_{u}\right) /\left(2.2 * P_{u}\right)$ can be found out. The $\left(K_{p}, K_{i}\right)$ values thus obtained from TL method are $(0.2,15)$ for boost mode and $(0.4,30)$ for buck mode.

\section{B. Fuzzy Logic Controller}

A rule based Fuzzy Logic Controller is created for quadratic buck-boost converter as in Fig 6. A FLC has to be created before the system is simulated in the MATLAB/SIMULINK. Using fuzzy logic tool box, a FIS file has to be created in FIS editor. Membership functions needed for this system is selected and accordingly rules were setup for the membership functions for the constant output.

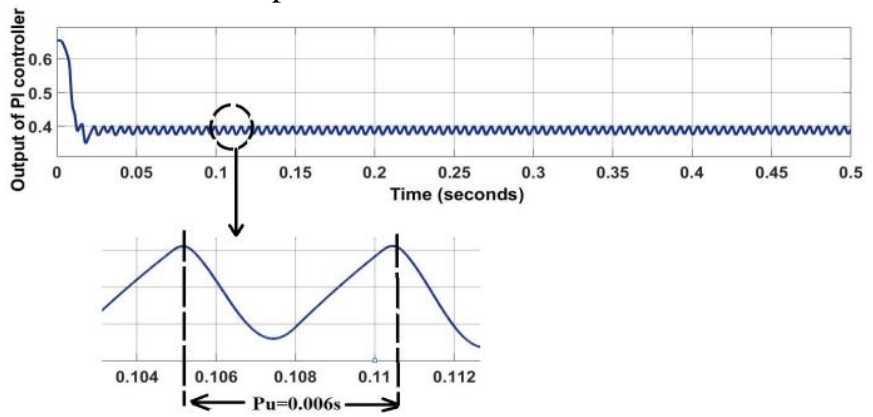

Fig. 6. Output of PI controller with $K_{u}=0.6$ (Boost Mode)

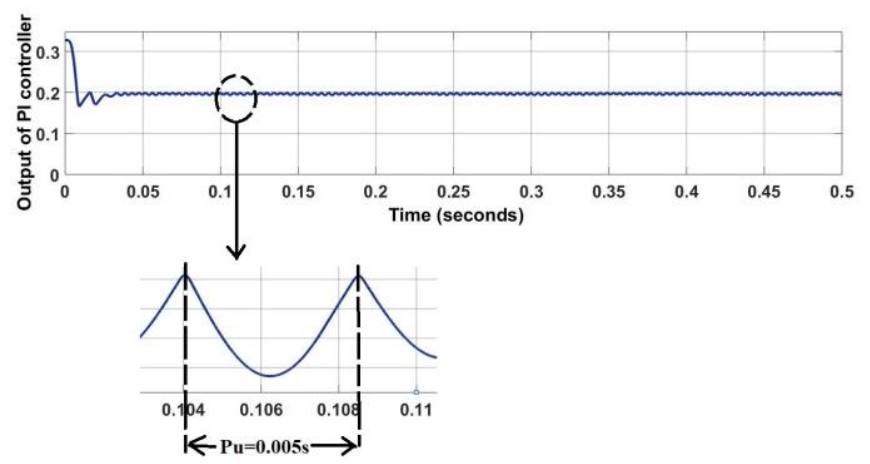

Fig. 7. Output of PI controller with $K_{u}=1.2$ (Buck Mode) 
The fuzzy rules map an input space to an output space by means of a list of IF-THEN statements. There are two input variables each with five linguistic levels, therefore the total number of possible fuzzy rules could be $5 * 5=25$. Table I illustrates the 25 fuzzy rules. The realization of a controller is obtained in the MATLAB/SIMULINK. The membership functions i.e. two inputs, an error(E), change in error(dE) and one output which is duty ratio control(dD) is created and 25 fuzzy rules are determined. Membership functions are shown in Fig. 8, Fig. 9 and Fig. 10.

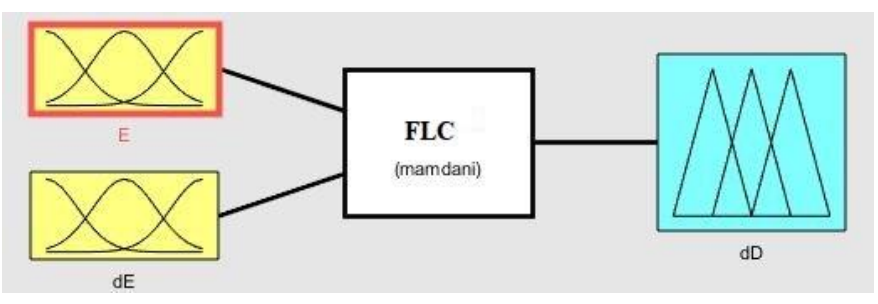

Fig. 8. Membership functions of FLC

In the Table I, NL means Negative Large, NS means Negative Small, Z means Zero, PS means Positive Small and PL means Positive Large. These are the possible variation that may occur in control variables.
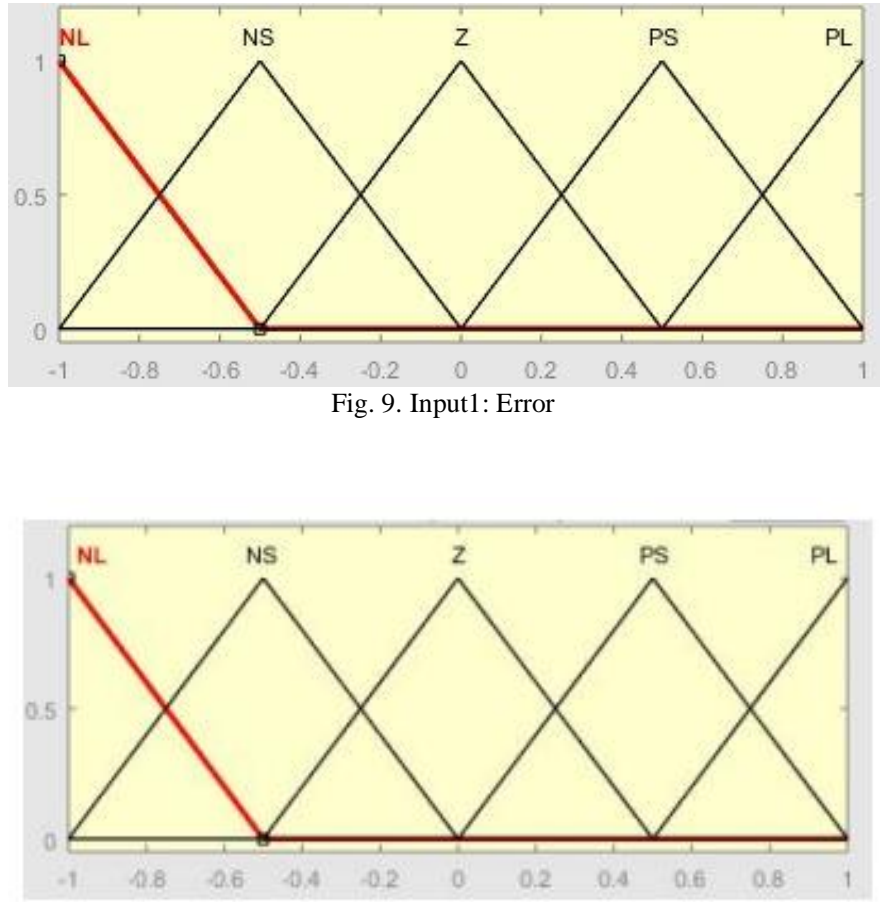

Fig. 10. Input2: Change in error

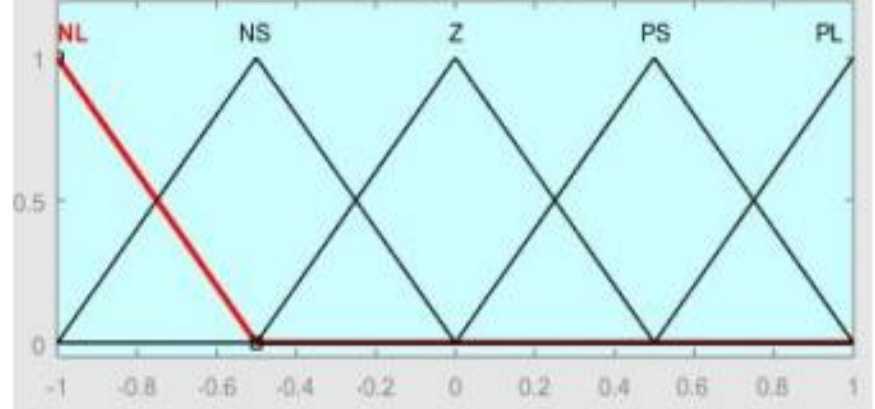

Fig. 11. Output:Duty ratio control

TABLE I FUZZY RULES

\begin{tabular}{|c|c|c|c|c|c|}
\hline E dE & NL & NS & $Z$ & PS & PL \\
\hline NL & NL & NL & NL & NS & Z \\
\hline NS & NL & NL & NS & Z & PS \\
\hline $\mathbf{Z}$ & NL & NS & Z & PS & PL \\
\hline PS & NS & Z & PS & PL & PL \\
\hline PL & Z & PS & PL & PL & PL \\
\hline
\end{tabular}

\section{RESULTS AND DISCUSSION}

For analysing the proposed system, the simulation model of proposed system is simulated using MATLAB. A FLC is created in FIS editor using a fuzzy logic toolbox. Parameter specifications taken for simulation are listed in the table (Table II).

TABLE II

PARAMETERS

\begin{tabular}{|c|c|c|c|}
\hline Sl.No. & Components & Symbol & Specifications \\
\hline 1 & Input Voltage & $V_{i n}$ & $25 \mathrm{~V}$ \\
\hline 2 & Output Voltage & $V o$ & $50 \mathrm{~V}$ \\
\hline 3 & Load Resistance & $R 1, R 2$ & $40 \mathrm{ohm}$ \\
\hline 4 & Inductors & $L_{1}$ & $100 \mu H$ \\
\cline { 3 - 4 } & & $L_{2}$ & $400 \mu H$ \\
\cline { 3 - 4 } & & $L_{3}$ & $3 \mathrm{mH}$ \\
\hline \multirow{2}{*}{5} & Capacitors & $C_{1}, C_{2}$ & $47 \mu F$ \\
\cline { 3 - 4 } & & $C_{3}, C_{4}$ & $660 \mu F$ \\
\hline 6 & Switching frequency & $\mathrm{fs}$ & $40 \mathrm{KHz}$ \\
\hline
\end{tabular}

\section{A. Open Loop}

The converter is first simulated in MATLAB as open loop without the controller to analyse the dual output and inductor currents. 


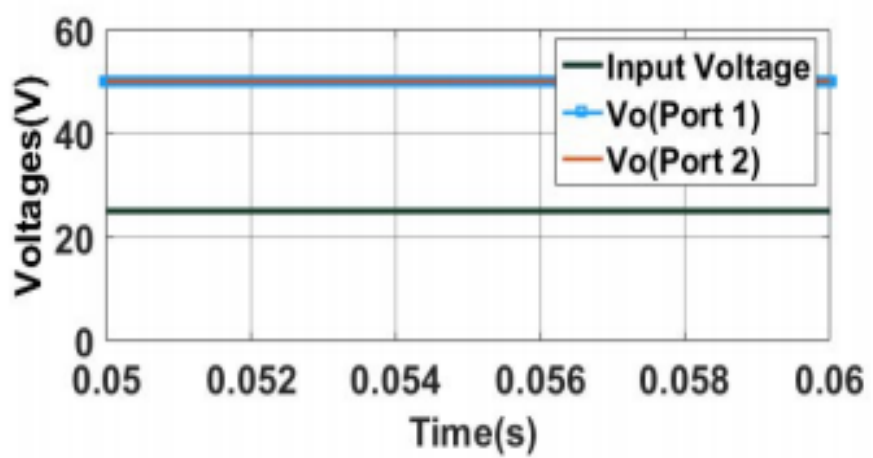

Fig. 12. Input and Output ports voltage

Fig. 12 shows the input and output ports voltage of the converter in open loop. Dual output voltages of $50 \mathrm{v}$ is obtained when an input voltage of $25 \mathrm{~V}$ is applied across the input of the converter.
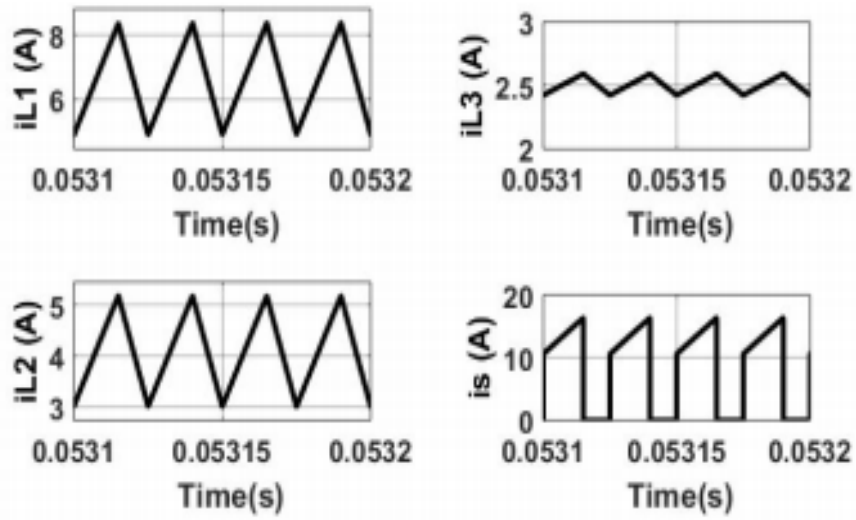

Fig. 13. Inductor currents $i_{L 1}, i_{L 2}, i_{L 3}$ and Switch current $i_{s}$

Fig. 13 shows current through inductors. Inductors get charged during $T_{\text {on }}$ and get discharged during $T_{\text {off }}$ of switch. The current flow through the switch is approximately equal to the sum of the three inductor currents when the switch is turned $\mathrm{ON}$. The proposed converter has continuous input port current and continuous output port current, so they do not require extra inductors and capacitors as input and output filters, to satisfy the EMI/EMC issues in practical applications.

\section{B. Closed Loop}

Closed-loop systems are designed to automatically achieve and maintain the desired output condition by comparing it with the actual condition. It does this by generating an error signal, which is the difference between the output and the reference input. In other words, a "closed-loop system" is a fully automatic control system in which its control action being dependent on the output in some way.

Converter was simulated in MATLAB using PI controller and then with fuzzy logic controller to analyse the performance.
Design criterias chosen for controller are $V_{o}=48 \mathrm{~V}$ for boost mode and $V_{o}=12 \mathrm{~V}$ for buck mode.

PI and fuzzy logic controller implementation was done in MATLAB. System response are compared for both the controller as shown in Fig. 14. It is evident that the fuzzy logic controller can provide better and faster response compared to PI controller.

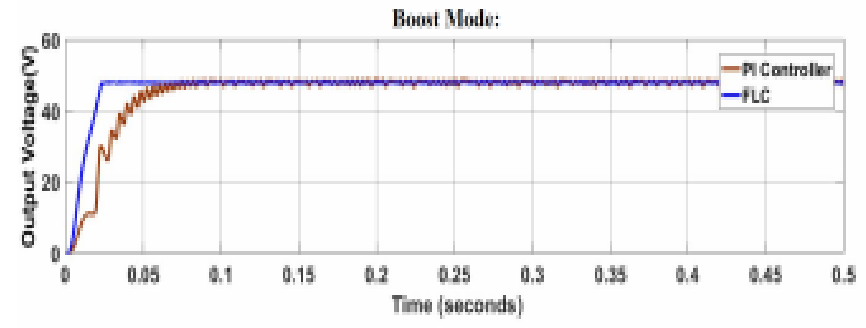

(a)

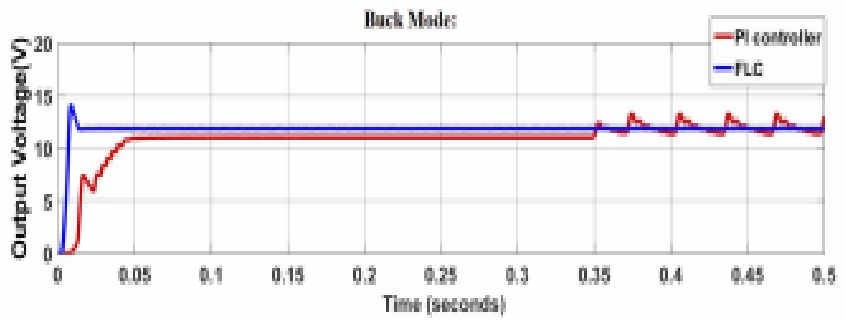

(b)

Fig. 14. Comparsion of output voltage for PI controller and FLC in (a)boost mode and (b)buck mode

Fig. 15 shows the input and output waveforms with variable irradiance from PV panel in buck mode. Dual output Voltage of $12 \mathrm{~V}$ is obtained. Even with variable irradiance from PV panel, FLC regulated the output in buck mode without any ripple.

Fig. 16 shows the input and output waveforms with variable irradiance from PV panel in boost mode. Dual output Voltage of $48 \mathrm{~V}$ is obtained. Even with variable irradiance from PV panel, FLC regulated the output at required value without any ripple.

The performance of fuzzy logic controller is further analysed with the large variation of input voltage. This large variation of input was simulated with help of signal builder in MATLAB. Fig. 17 and Fig. 18 show that the output voltage remains constant as per the design requirements of $48 \mathrm{~V}$ in boost mode and $12 \mathrm{~V}$ in buck mode given to the controller respectively. 

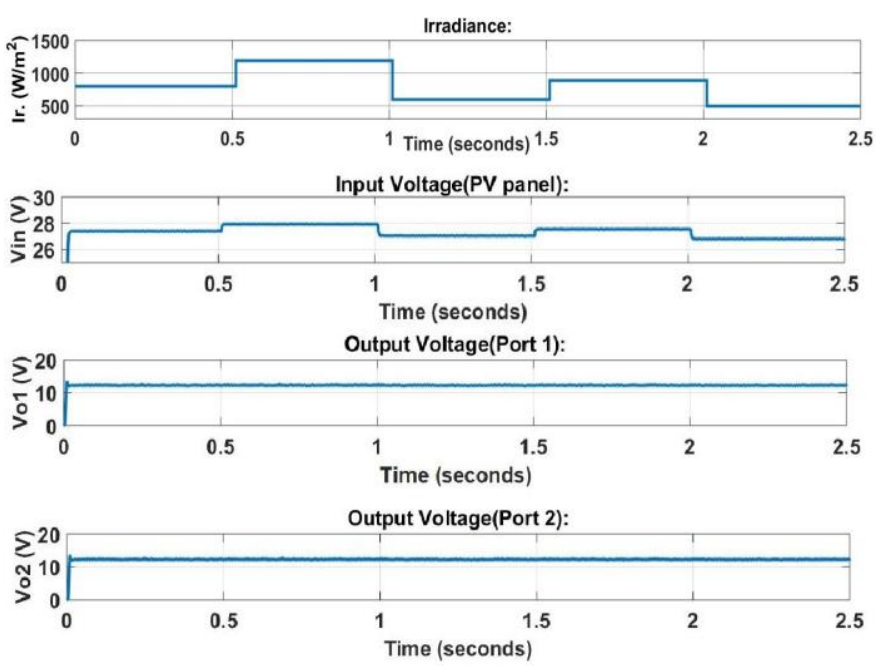

Fig. 15. Input and output waveforms for varying irradiance-Buck Mode
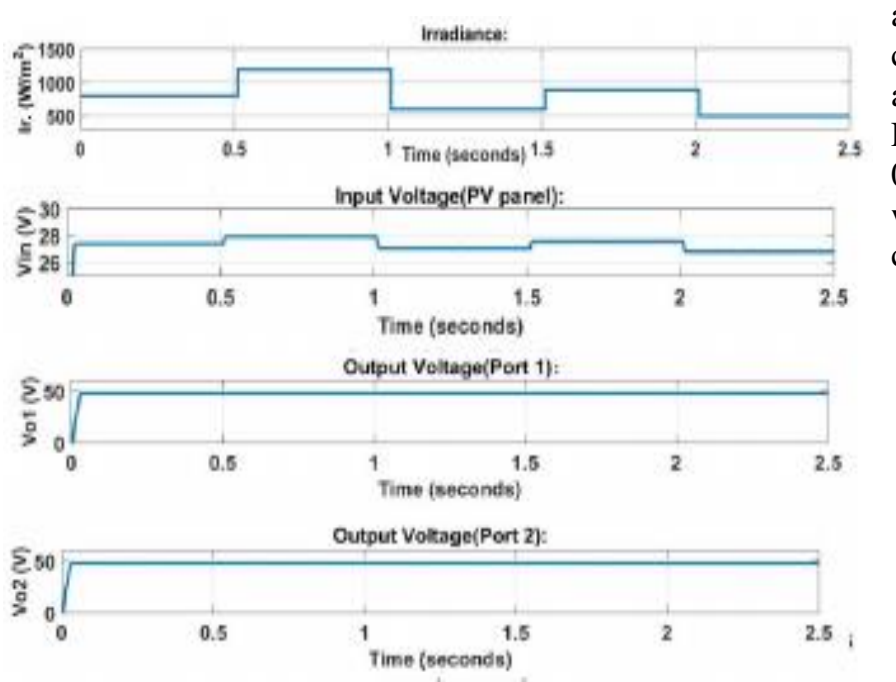

Fig. 16. Input and output waveforms for varying irradiance-Boost Mode

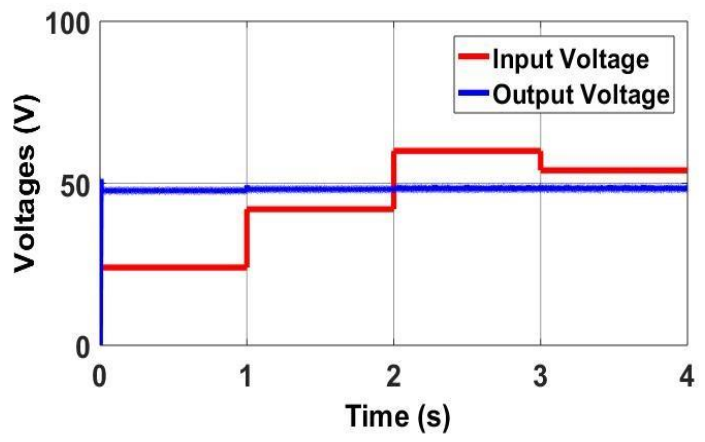

Fig. 17.Input and output waveforms for varying input(Boost Mode) with FLC

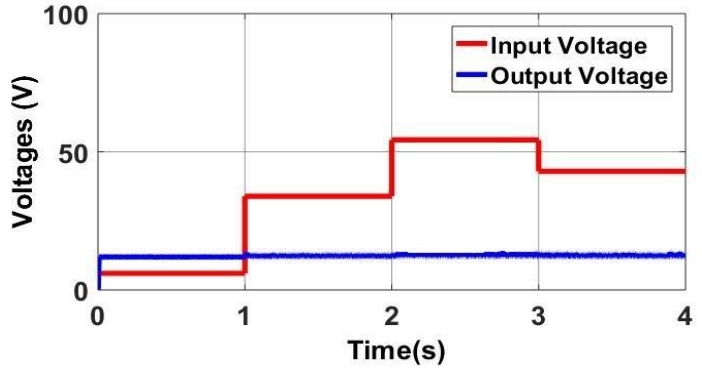

Fig. 18. Input and output waveforms for varying input(Buck Mode) with FLC

\section{PERFORMANCE COMPARISON}

The comparsion of output voltage for PI controller and FLC in boost mode and buck mode can be seen in Fig. 14. Simulation outcome of proposed converter shows that settling time of PIC in boost mode is 0.07 seconds whereas for FIC it is reduced to 0.03 seconds, similarly in buck mode in PIC it is 0.05 seconds and in FLC its reduced to 0.01 seconds where fuzzy logic control performance is greatly improved. And also ripple amount in output voltage is comparitively more in PIC than FLC in boost mode. Eventhough output is well regulated till $0.35 \mathrm{~s}$ in buck mode for PIC, it looses its stable output after $0.35 \mathrm{~s}$ which may affect overall system. This controller performance comparison is shown in Table III.

TABLE III CONTROLLER PERFORMANCE COMPARISON

\begin{tabular}{|c|c|c|c|}
\hline \multicolumn{2}{|c|}{ Factors } & $\begin{array}{c}\text { PI CONTROLLER } \\
\text { (TL method) }\end{array}$ & FLC \\
\hline \multirow{2}{*}{$\begin{array}{c}\text { Settling } \\
\text { Time }\end{array}$} & Buck mode & $0.05 \mathrm{~s}$ & $0.01 \mathrm{~s}$ \\
\cline { 2 - 4 } & Boost mode & $0.07 \mathrm{~s}$ & $0.03 \mathrm{~s}$ \\
\hline $\begin{array}{c}\text { Disturbance } \\
\text { in output }\end{array}$ & Buck mode & Yes & No \\
\cline { 2 - 4 } & Boost mode & Yes & No \\
\hline
\end{tabular}

Fig. 19 shows the comparison of output ripple in existing[Fig. 2] and proposed converter topology. The ripples present in the output voltage is less than $1 \%$ in the proposed system.

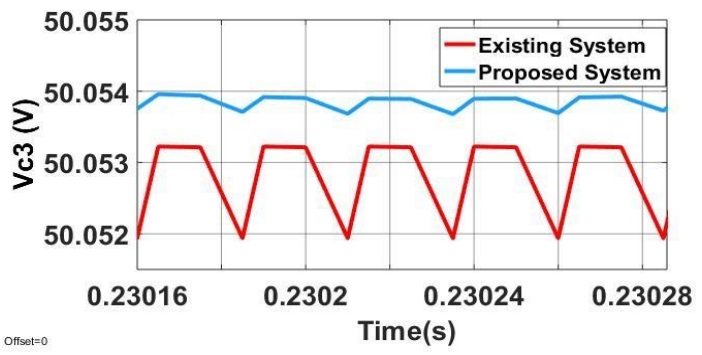

Fig. 19. Comparison of output ripple in existing and proposed converter topology 


\section{International Journal of Engineering Applied Sciences and Technology, 2021 Vol. 6, Issue 1, ISSN No. 2455-2143, Pages 181-189 \\ Published Online May 2021 in IJEAST (http://www.ijeast.com)}

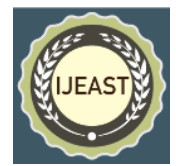

TABLE IV

TOPOLOGY COMPARISON

\begin{tabular}{|c|c|c|}
\hline Factors & Existing system & Proposed system \\
\hline Dual output & No & Yes \\
\hline Output voltage ripple & $1.2 \mathrm{mV}$ & $0.4 \mathrm{mV}$ \\
\hline Controller & No & Yes \\
\hline
\end{tabular}

Table IV shows the comparison of the proposed topology of converter with the existing topology of converter. With the dual output voltage, there is an added advantage of reduced voltage ripple.

\section{CONCLUSION}

Dual output quadratic buck boost converter offers a wide range of conversion ratio and uniform current sharing with an added advantage of reduced output ripple. The proposed converter has an inductor in the input port as well as an inductor in the output port, which is capable of making the input port current and output port current to be continuous and contributes to the simplification of the design of input and output filters. The circuit is simulated in MATLAB/SIMULINK software to substantiate the circuit function. The conventional control i.e. Proportional-Integral (PI) controller is differentiated from smart/intelligent fuzzy logic controller (FLC) in both buckboost mode. Simulation outcome and investigation of proposed converter shows that settling time of PIC in boost mode is 0.07 seconds whereas the for FLC it is reduced to 0.03 seconds, similarly in buck mode in PIC it is 0.05 seconds and in FIC its reduced to 0.01 seconds, where fuzzy logic control performance is greatly improved and superior as shown in the Table III.

\section{REFERENCES}

[1] Zhang, Neng, Guidong Zhang, K. See and B. Zhang, "A Single-Switch Quadratic Buck-Boost Converter With Continuous Input Port Current and Continuous Output Port Current. (2012)",IEEE Transactions on Power Electronics, vol.33, no.5, (pp. 4157-4166).

[2] G. Moschopoulos, "Quadratic power conversion for industrial applications(2010)", in proceedings of 25th Annual IEEE Applied Power Electronics Conference Exposition, (pp. 1320-1327).

[3] X. L. Wei, K. M. Tsang, and W. L. Chan, "Non-linear PWM control of single-switch quadratic buck converters using internal model(2009)", IET Power Electronics, vol. 2, no. 5, (pp. 475-483).

[4] J. A. M. Saldana, J. L. Ramos, E. E. C. Gutierrez, and M. G. O. Lopez, "Average current-mode control scheme for a quadratic buck converter with a single switch(2012)," IEEE Transactions on Power Electronics, vol. 23, no. 1, (pp. 485-490).

[5] J. J. Chen, B. H. Huang, C. M. Kung, W. Y. Tai, and Y. S. Hwang, "A new single-inductor quadratic buck converter using average-currentmode control without slopecompensation(2010)", in proceedings of 5th IEEE
Conference of Industrial Electronics Applied, (pp. 10821087).

[6] J.A.M. Saldana, R. L. Palomo, and E. P. Hernandez, "Parameters selection criteria of proportional-integral controller for a quadratic buck converter(2014)", IET Power Electronics, vol. 7, no. 6, (pp. 1527-1535).

[7] A. Ayachit and M. K. Kazimierczuk, "Open-loop small signal transfer functions of the quadratic buck PWM DCDC converter in CCM(2014)", in proceedeings of 40th Annual Conference IEEE Industrial Electronics, (pp. 1643-1649).

[8] J. L. Ramos, M. G. O. Lopez, L. H. D. Saldierna, and J. A. M. Saldana, "Switching regulator using a quadratic boost converter for wide DC conversion ratios(2009)," IET Power Electronics, vol. 2, no. 5, (pp. 605-613).

[9] J. A. M. Saldana, R. L. Palomo, E. P. Hernandez, and J. L. G. Martinez, "Modelling and control of a DC-DC quadratic boost converter(2014) ", IET Power Electronics, vol. 7, no. 1, (pp. 11-22).

[10] Polanco, "Robust sliding-mode control design for a voltage regulated quadratic boost converter(2015)", IEEE Transactions of Power Electronics, vol. 30, no. 4, pp. 2313-2327.

[11] M. A. A. Saffar, E. H. Ismail, and A. J. Sabzali, "High efficiency quadratic boost converter(2012)", in proceedings of 27th Annual IEEE Applied Power Electronics Conference, (pp. 1245-1265).

[12] Pedro Mart'in Garc'ia-Vite; Julio C. Rosas-Caro , Ana Lidia Mart'inezSalazar, "Quadratic buck-boost converter with reduced input current ripple and wide conversion range(2019)," IET Power Electronics, vol. 12, No. 15, (pp. 3977-3986).

[13] Vitor Fern ao Pires, Senior Member, IEEE, Daniel Foito, and Armando Cordeiro "A DC-DC Converter With Quadratic Gain and Bidirectional Capability for Batteries/Supercapacitors(1989)" ,IEEE Transactions on Industry Applications, vol. 54, no. 1, (pp. 274-285).

[14] S. Miao, F. Wang, X. Ma, "A new transformerless buckboost converter with positive output voltage(2016)," IEEE Transactions on Industrial Electronics, vol. 63, no. 5, pp. $2965-2975$.

[15] V. M.. Pacheco, A. J. D. Nascimento, V. J. Farias, “A quadratic buck converter with lossless commutation(2000)", IEEE Transaction on Industrial Electronics, vol. 47, no. 2,(pp. 264 - 272).

[16] D. Maksimovic and S. Cuk, "General properties and synthesis of PWM DC-to-DC converters(1989)", in proceedings of IEEE Power Electronics Conference, (pp. 515-525).

[17] D. Maksimovic and S. Cuk, "Switching converters with wide DC conversion range(1991)", IEEE Transaction of Power Electronics, vol. 6, no. 1, (pp. 151-157). 
[18] Hamid Behjati, Ali Davaudi, "A multiple input multiple output DC-DC converter(2013)," IEEE Transaction on Industry Applications, Vol. 49, No. 3, (pp. 445 - 453). 